\title{
anarquismo e descolonização: possibilidades para pensar a infância
}

\author{
olivia pires coelho ${ }^{1}$ \\ universidade federal do rio grande do sul - brasil \\ maria carmen silveira barbosa ${ }^{2}$ \\ universidade federal do rio grande do sul - brasil
}

resumo

Este artigo pretende contribuir com a reflexão acerca do Pós-Colonialismo e o Anarquismo a partir da ótica das práticas descolonizadoras da Infância. O objetivo de socializar esta reflexão, parte integrante das investigações para a dissertação de Mestrado em Educação (Linha de Pesquisas - Estudos da Infância) é construir novos olhares acerca do que entendemos por posições pós-colonialistas e anarquistas frente a educação das crianças pequenas. Acreditamos, portanto, que a socialização das elaborações e das análises teóricas é fundamental para o exercício de uma ciência democrática. Pois é no diálogo que as diferenças e complementações se encontram. É pertinente, também, salientar que esta pesquisa é marginal. Marginal porque não está centrada nos discursos do eixo principal dos Estudos da Infância: não é um discurso de cunho pedagógico, não é um discurso da Psicologia tampouco da Pediatria. Estamos tratando da Infância sob a ótica nos Movimentos Sociais, em especial, das discussões elaboradas pelo movimento Anarquista e da Desescolarização, esperando contribuir para os debates epistemológicos no seio das reflexões acerca dos elementos que constituem a construção da Educação enquanto Ciência Social, com compromisso político e efetivamente revolucionário.. Para finalizar, esta investigação e seus catalisadores não tem como objetivo a busca de uma verdade cristalizada: o objetivo é a desconstrução das nossas próprias amarras capitalistas enquanto cientistas, investigadores, professores, educadores e pensadores/as.

palavras-chave: pós-colonialismo; anarquismo; estudos da infância.

\section{anarquismo y descolonización: posibilidades para pensar la infancia}

resumen

Este artículo tiene como objetivo contribuir con la reflexión sobre el poscolonialismo y el anarquismo desde la perspectiva de las prácticas de descolonización de la niñez. El objetivo de compartir esta reflexión, parte de la investigación para la tesis de Maestría en Educación (Línea de Investigación - Estudios de Infancia), es construir nuevas visiones acerca de lo que queremos decir con posiciones anarquistas y post-coloniales frente a la educación de los niños y niñas pequeñas. Creemos, por tanto, que la socialización de las elaboraciones y análisis teóricas es fundamental para el ejercicio de una ciencia democrática. Pues es, en el diálogo que las diferencias y complementaciones se encuentran. Es pertinente señalar también que esta investigación es marginal. Marginal, ya que no se centra en los discursos del eje principal de la educación de la infancia: no es un discurso de carácter pedagógico, no es un discurso de la psicología ni de la pediatría. Nos posicionamos ante la niñez desde la perspectiva de los movimientos sociales, en particular de los debates del movimiento anarquista y de desescolarización (unschooling), con la esperanza de contribuir a los debates epistemológicos desde los elementos de la construcción de la educación como Ciencias Sociales, con compromiso político y

\footnotetext{
${ }^{1}$ E-mail: olivia.p.coelho@gmail.com

2 E-mail: licabarbosa@ufrgs.br
} 
efectivamente revolucionaria. Por último, esta investigación y sus catalizadores no tienen como objetivo la afirmación de una verdad cristalizada: el objetivo es deconstruir nuestros propias amarras capitalistas como científicos, investigadores, profesores, educadores y pensadores /as.

palabras clave: poscolonialismo; anarquismo; estudios de infancia.

\section{anarchism and decolonization: possibilities for thinking about childhood}

abstract

This article intends to contribute to the reflections on Postcolonialism and Anarchism under the perspective of Childhood decolonization practices. The purpose of socializing this analysis, part of the master's in Education thesis (research line - Childhood Studies) is to build new perspectives into the comprehension on postcolonial and anarchist practices on early childhood education. We believe, therefore, that sharing creations and theoretical analysis is fundamental for the exercise of a democratic science. Because it is within dialogue that the differences and the contributions meet. It's also pertinent to point out that this research is marginal. Marginal because it is not focused on the Childhood Studies mainstream discourse: it is not a pedagogical discourse, nor a psychological neither a pediatric one. We are focusing on childhood under the perspective of the Social Movements, specially the anarchist and the Unschooling perspective, hoping to contribute to the epistemological debates within the reflections about the elements that constitute the development of Education as a Social Science, effectively political and revolutionary engaged. To conclude, this investigation and its catalyzers are not seeking a crystalized truth: we are hoping to lose our own capitalists ties, as scientists, researchers, teachers, educators and thinkers.

keywords: postcolonialism; anarchism; childhood studies. 
anarquismo e descolonização: possibilidades para pensar a infância

\section{os estudos pós-coloniais e decoloniais}

$\mathrm{Na}$ América Latina, os estudos pós-coloniais/decoloniais se constituem em um campo interdisciplinar, envolvendo investigações e análises de áreas, como a Sociologia, Ciência Política, Estudos de Gênero e Feminismo e também a Educação. É pertinente salientar que há, no mínimo, dois entendimentos de conceituação possíveis para o termo "pós-colonial". Uma que se refere ao tempo histórico do fim do período colonial em países que vivenciaram a exploração e dominação por meio da ocupação e domínio, majoritariamente, europeu e norteamericano. Por exemplo, o fim do período colonial no Brasil, em 1888, fim do período colonial na Austrália em 1901, fim do período colonial em Gana, em 1957. Outra conceituação pertinente está no lócus de definição do que vem a ser, então, os Estudos Pós-Coloniais, que emergem no século XX e procuram aprofundar a densidade da experiência colonial flexibilizando-as dos eixos de tempo e espaço.

Entendemos "pós-colonial" como, de acordo com os autores que organizam o livro Infâncias e Pós-Colonialismo (FARIA et al., 2015), a vertente de olhar minucioso sobre as estratégias de violência, subordinação e desumanização que produzem o "outro"; sendo o "outro": a criança, o/a negro/a, o/a indígena, o/a cigano/a, os LGBTT's (lésbicas, gays, bissexuais, transexuais, travestis), enfim, todos que não são o homem branco, heterossexual, patriarcal, europeu: o colonizador. O pós-colonialismo faz parte de um conjunto de teorias (junto com, por exemplo, os Estudos Culturais) que pretende resgatar a autonomia e as narrativas dos grupos compreendidos como"os de baixo"., denominação utilizada pelo o importante autor do campo da Geografia, Milton Santos (apud FARIA et al., 2015, p. 11):

A teoria pós-colonial parte do princípio que a Colonização não acabou quando a ocupação dominante se retirou dos países colonizados, pois ainda há um longo processo de descolonização da imaginação, das práticas autoritárias, das percepções hierarquizadas da construção do nosso próprio imaginário social enquanto habitantes e cidadãos de um país que foi brutalmente colonizado. De 
acordo com Fanon (apud. FARIA et al., 2015, p. 13): “A descolonização é, na verdade, a produção de espaços para os/as novos/as protagonistas sociais subalternizados/as pela colonização".

A herança colonial deixa marcas profundas na organização da sociedade (acreditamos não existir obra que aborde tão bem esta questão como Eduardo Galeano - As veias abertas da América Latina), portanto há configurações latentes que foram herdadas do processo de colonização, como, por exemplo, o racismo estrutural e institucional, o machismo sofrido por mulheres na América Latina e em grande parte do continente africano, o silenciamento das crianças, a exclusão dos povos indígenas. É nesse contexto contemporâneo que a teoria pós-colonial analisa a herança do processo colonizador. Ballestrin (2013, p. 91) argumenta que: “Mesmo que não linear, disciplinado e articulado, o argumento pós-colonial em toda sua amplitude histórica, temporal, geográfica e disciplina percebeu a herança colonial e intercedeu pelo colonizado."

Rhadika Viruru (2005, p. 9) nos fala sobre a importância de adotar um posicionamento político ativista na teoria pós-colonial: “[...] post-colonial theory is not limited to the study of how nations have recovered from colonization but is more concerned with the adopting of an activist position, seeking social transformation." Ou seja, há uma identidade presente nos estudos pós-coloniais, no que diz respeito a quem produz esse conhecimento, tratam-se de autores e militantes que estão envolvidos em movimentos sociais e movimentos de resistência, especialmente na América Latina, África e Ásia. É uma teorização constituída na luta.

Traçar uma genealogia dos Estudos Pós-Coloniais é uma tarefa árdua. Como analisa Ballestrin (2013, p. 92) “aquilo que é considerado clássico na literatura pós-colonial é passível de questionamento". Ainda de acordo com a mesma autora (2013, p. 92-94) há o que é reconhecido enquanto "tríade francesa": Albert Memmi com Retratos do colonizado precedido de retrato do colonizador (1947), Aimé Césaire com Discurso sobre o colonialismo (1950), e Franz Fanon com Os condenados da terra (1961), consideradas as primeiras obras que serviram de portavoz para os colonizados enquanto estes ainda tinham suas vozes silenciadas. 
Juntamente à tríade francesa, a publicação de Orientalismo por Edward Said em 1987 é considerado, de acordo com Viruru (2005, p. 8) como:

[...] a crucial moment in the emergence of postcolonial theory. The then revolutionary concept that the Orient was a European political, sociological, military, ideological, scientific, imaginative and discursive creation opened the door to many other such discursive analyses.

Outro momento importante para a consolidação dos estudos pós-coloniais enquanto um movimento epistêmico, intelectual e político (BALLESTRIN, 2013, p. 92-94) foi a formação do Grupo de Estudos Subalternos que tinha como projeto principal “analisar criticamente não só a historiografia colonial da Índia feita por ocidentais europeus, mas também a historiografia eurocêntrica nacionalista indiana." (GROSFOGUEL apud. BALLESTRIN, 2013, p. 92). Partha Chatterjee, Dipesh Chakrabarty e Gayatri Spivak são consideradas como "a tríade sagrada" do pós-colonialismo, trazendo a contribuição, que hoje é entendida como uma das principais concepções dos estudos pós-coloniais: "não só o subalterno não pode falar como também o intelectual pós-colonial não pode fazer isso por ele. " (BALLESTRIN, 2013, p. 92). Trazendo, então, a contribuição de que os "sujeitos colonizados" é que devem ser donos de suas próprias narrativas.

No campo da crítica literária e dos Estudos Culturais os exponentes são Homi Bhabha com O Local da Cultura (1994), Stuart Hall com Da Diáspora (2003) e Paul Gilroy com O Atlântico Negro (1993).

A América Latina está inserida no debate pós-colonial a partir de 1998 com o Manifesto inaugural del Grupo Latinoamericano de Estudios Subalternos sob a coordenação de Eduardo Mendieta e Santiago Castro-Goméz, juntamente com a coletânea Teorias sin disciplina: latinoamericanismo, poscolonialidad y globalización em debate (BALLESTRIN, 2013, p. 95).

A voz mais radical do grupo de estudos subalternos na América Latina tem sido Walter Mignolo, que, segundo a leitura de Castro-Goméz apud (BALLESTRIN, 2013, p. 95):

Walter Mignolo aproveita também alguns elementos das teorias póscoloniais para realizar uma crítica dos legados coloniais na América Latina. Mas, à diferença de Ileana Rodríguez e de outros membros do Grupo de Estudos Subalternos, Mignolo pensa que as teses de Ranajit Guha, Gayatri Spivak, Homi Bhabha e outros teóricos indianos não deveriam ser simplesmente assumidas e traduzidas para uma análise do 
caso latino-americano. Ecoando críticas anteriores de Vidal e Klor de Alva, Mignolo afirma que as teorias pós-coloniais têm seu lócus de enunciação nas heranças coloniais do império britânico e que é preciso, por isso, buscar uma categorização crítica do ocidentalismo que tenha seu lócus na América Latina.

Mignolo critica o imperialismo dos estudos culturais e subalternos que não realizaram uma ruptura adequada com autores eurocêntricos (BALLESTRIN, 2013, p. 95) e exige um olhar próprio da América Latina. Isto porque seria essencial a crítica de que não seria possível aderir um discurso feito em contextos distintos, sendo necessária uma especificidade epistemológica latino-americana.

Constituído no final dos anos 1990, o grupo Modernidade/Colonidade trouxe a perspectiva pós-colonial de maneira mais ampla no debate latinoamericano, apoiado pela CLACSO (Consejo Latinoamericano de Ciencias Sociales), o grupo lançou a publicação coletiva $L a$ Colonialidad del saber: eurocentrismo y ciências sociales. Particularmente, consideramos esta obra a mais importante para pensarmos Colonialidade na América Latina, pois reúne autores como Enrique Dussel, Anibal Quijano e Walter Mignolo, entre outros. A maior contribuição do grupo Modernidade/Colonidade é evidenciar a tripla dimensão da reprodução da colonialidade: o poder, o saber e o ser.

É importante frisar, portanto, que o debate dito pós-colonial na América Latina também foi estabelecido por uma vertente distinta. Os paradigmas sobre colonialidade na América Latina referem-se, essencialmente, a reflexão acerca do processo colonizador europeu que saqueou e moldou as sociedades que aqui se desenvolviam. Especialmente porque os pensadores latino-americanos concentravam-se na dicotomia Modernidade/Colonialidade. Refletindo acerca das indagações do ranço colonial: o moderno versus o selvagem, a metrópole versus a colônia. Para compreensão deste paradigma, chamado por muitos pensadores latino-americanos de decolonial, citamos Dussel (2005, p.29) sobre a invenção da Modernidade na América Latina e sobre as "periferias" do mundo, que julgamos ser bastante didático para entender a lógica dos estudos pós-coloniais. Dussel trata a Modernidade no sentido imposto pelo colonizador, no sentido de progresso e, ao falar da civilização moderna, refere-se às sociedades pós processos colonizatórios 
e aos povos europeus, que trouxeram a noção de "civilizado" versus "selvagem" para América Latina e outros povos colonizados.

1. A civilização moderna autodescreve-se como mais desenvolvida e superior (o que significa sustentar inconscientemente uma posição eurocêntrica). 2. A superioridade obriga a desenvolver os mais primitivos, bárbaros, rudes, como exigência moral. 3. O caminho de tal processo educativo de desenvolvimento deve ser aquele seguido pela Europa (É, de fato, um desenvolvimento unilinear e à europeia o que determina, novamente de modo inconsciente, a "falácia desenvolvimentista"). 4. Como o bárbaro se opõe ao processo civilizador, a práxis moderna deve exercer em último caso a violência, se necessário for, para destruir os obstáculos dessa modernização (a guerra justa colonial). 5. Esta dominação produz vítimas (de muitas e variadas maneiras), violência que é interpretada como um ato inevitável, e com o sentido quase-ritual de sacrifício; o herói civilizador reveste a suas próprias vítimas da condição de serem holocaustos de um sacrifício salvador (o índio colonizado, o escravo africano, a mulher, a destruição ecológica, etc). 6. Para o moderno, o bárbaro tem uma "culpa" (por oporse ao processo civilizador) que permite a "Modernidade" apresentar-se não apenas como inocente, mas como "emancipador" dessa "culpa" de suas próprias vítimas. 7. Por último, e pelo caráter "civilizatório" da "Modernidade", interpretam-se como inevitáveis os sofrimentos ou sacrifícios (os custos) da "modernização" dos outros povos "atrasados" (imaturos), das outras raças escravizáveis, do outro sexo por ser frágil, etc.

É por estes aspectos: Poder, Saber e Ser que abordaremos a questão PósColonial em sua relação com o Anarquismo. Mas, antes, é preciso falar um pouco sobre a Educação Anarquista em questão.

\section{anarquismo nas suas relações com a educação}

O Estado age na educação como uma máquina de controle. As escolas só funcionam sob as indicações das políticas educacionais, seus parâmetros e diretrizes curriculares. Coloniza o pensamento e as ações de professores, crianças e famílias. O anarquismo propõe uma visão diferente de Educação, no que se refere a descolonizar esses pensamentos e práticas; seria mais adequado referir-se a "anarquismos", pois existem tantos anarquismos quanto anarquistas, considerando a grande diversidade de correntes e posicionamentos teóricos e estratégias de militância divergentes no movimento.

O anarquismo, em suas contribuições para Educação, em Gallo (2007, p. 21 22), é entendido como um conjunto de princípios geradores, formado essencialmente por: autonomia individual, autogestão social, internacionalismo e 
ação direta (GALLO, 2007, p. 21 - 22). Antes de abordar especificamente este conjunto de princípios geradores, resgatamos o conceito-verbete de Educação no Pequeno Dicionário de Ideias Libertárias do Anarcossindicalista brasileiro Edgar Rodrigues:

Educar não é o mesmo que instruir. A instrução corresponde ao aprendizado de um ofício, atua no desenvolvimento das faculdades intelectuais, enquanto a educação atinge o homem no seu todo. Um analfabeto pode ser educado e um homem instruído, possuidor de títulos doutorais, universitários, um estúpido carente de educação, um incapaz diante da vida. A educação atinge todos os setores em que o homem exerce a inteligência, a memória, a vontade, os sentimentos, o comportamento dentro do grupo, no seu meio e na sociedade. Educação envolve compreensão, tolerância, respeito mútuo, solidariedade humana; não é o ensino de palavras de espaço limitado, é o ensino de fatos, pela natureza, pela vida. Educação - não é convencer a criança e o adulto de que "o homem moral e o bom cidadão deve aprovar, amar o regime social sob o qual vive e que, é imoral, criminoso, criticá-lo, procurar que se modifique, e ainda mais, lutar para destruí-lo. " (Paul Robin) Educação é a forma de ensino expurgado de todas as inutilidades clássicas, integradas as necessidades da vida, tratada individualmente, como as plantas, cada uma independentemente. E, acima de tudo, a preparação do homem para a liberdade, para a criatividade e a solidariedade. Educar é contribuir para formar caráteres retos, despertar o amor pela humanidade, converter o homem no amigo do homem, responsáveis por si, pelo grupo, em irmão do homem. (RODRIGUES, 1996, p. 21)

Sendo assim, então, sistematizamos as contribuições dos princípios geradores do anarquismo - fundamentados em Gallo (2007, p. 21 - 22) - na seguinte estrutura:

Autonomia individual: o entendimento do sujeito, integrante e ativo em uma sociedade. $\mathrm{O}$ autor aborda que a ação anarquista deve ser pensada considerando os indivíduos que compõe esta sociedade e ser voltada para estes, de acordo com seus contextos.

Auto-gestão social: organização dos indivíduos, contrária aos poderes institucionalizados, essencialmente estatais, e hierarquizados.

Internacionalismo3: a potência de construção de uma sociedade libertária independentes da noção de país e pátria - noção europeia aliada à colonização e hierarquização das unidades geopolíticas e territórios.

\footnotetext{
${ }^{3}$ Internacionalismo é um conceito muito potente para o debate pós-colonial/decolonial, uma vez que propõe um entendimento libertário sobre os estados-nações e problematiza a noção de pátria/país e a hierarquização das unidades geopolíticas e territórios.
}

342 childhood \& philosophy, rio de janeiro, v. 13, n. 27, maio-ago. 2017, pp. 335-352 issn 1984-5987 
Ação direta: tática de luta anarquista que propõe que os indivíduos, em organização auto-gestionada, constituam as bases para revolução (anticapitalista). A Educação é considerada um elemento da tática de luta anarquista.

Compreendemos que os princípios geradores do anarquismo nos fornecem as bases para pensar, então, o paradigma anarquista da educação. Gallo (2007, p. 23) afirma que "Os anarquistas assumem de vez tal caráter político da educação, querendo coloca-la não mais a serviço da manutenção de uma ordem social, mas sim de sua transformação, denunciando injustiças e desmascarando os sistemas de dominação, despertando nos indivíduos a consciência da necessidade de uma revolução social." O autor, acima citado, Gallo (2007, p. 30) faz alusão à Caetano Veloso em uma feliz analogia à Educação Anarquista ao cantar "alguma coisa está fora da nova ordem mundial".

Na lógica formal da Pedagogia a Educação Anarquista está à margem, é marginal. Põe em cheque uma questão essencial para pensarmos o paradigma póscolonial/decolonial e a educação das crianças pequenas: o poder. Traz à tona o debate acerca da subalternidade dos estudantes frente à coerção institucional hierarquizada dos ambientes de caráter unicamente escolar-formal - considera que há potência para além destes espaços. Mas não somente em outros espaços, mas que há potência nos corpos e nas mentes: o que é revolucionário diante do contexto em que crianças e estudantes são entendidos como sem história, direitos e não produtores de cultura. A criança e o estudante - em contextos institucionalizados e formais, colonizados - não Pode, não Sabe e não É. 


\section{pós-colonialismo e anarquismo - suas relações com a educação das crianças}

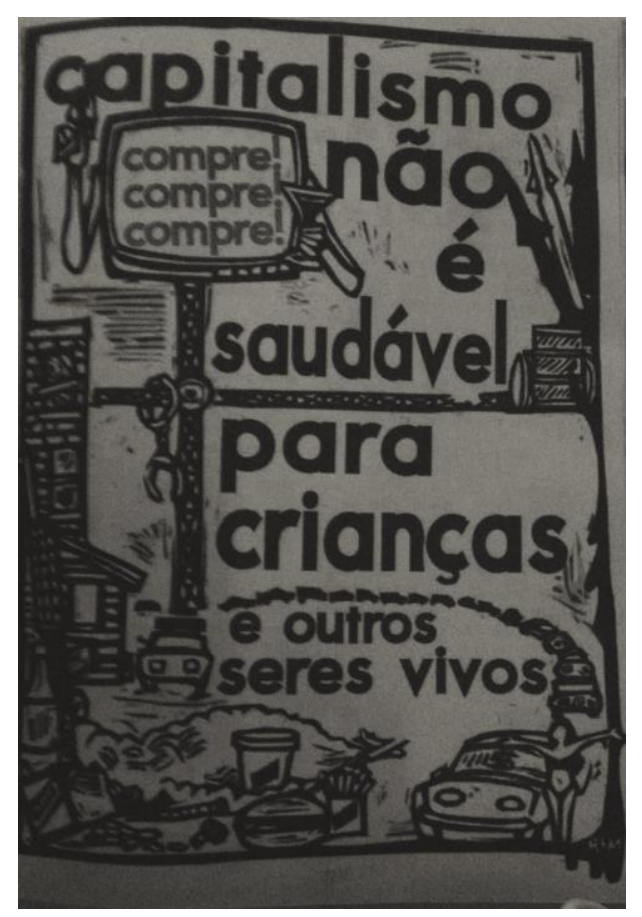

Figura 1: Capitalismo não é saudável para crianças e outros seres vivos. Intervenção artística. Autor prefere permanecer anônimo. 2016.

O debate acerca das possíveis relações entre o pós-colonialismo em educação e a educação anarquista ainda é praticamente inexistente. Pensamos nesse artigo em estabelecer relações entre ambos, pois eles possuem uma vertente epistemológica muito similar, especialmente no que se refere as concepções de Poder, Saber e Ser. Há muito da realidade europeia nos livros sobre Pedagogia Anarquista e os autores trabalhados na temática são, majoritariamente, homens europeus. Assim como na discussão sobre colonialidade, o debate acerca do "discurso único" se "repete" na relação com as crianças - apenas há um discurso aceitável, oficial, correto: o sobre/do adulto. Gallo (2007, p. 49) afirma que uma Educação Anarquista só poderia ser a luta contra a alienação (alienação capitalista do esquecimento dos indivíduos como seres complexos, integrais, com direito à igualdade, e à liberdade). Porém, onde estariam as crianças, em especial as crianças pequenas, neste debate? O que criança pequena pode, sabe e é?

O que trazemos para o debate é: o que anarquismo e o pós-colonialismo estão pensando sobre a dominação etária? Nas reflexões e práticas pedagógicas pós-coloniais/decoloniais as crianças estão envolvidas no debate? Se não, não 
seria por um resquício da colonialidade, do poder que nós, adultos, exercemos sobre a existência das crianças?

Posicionar-se no paradigma decolonial nos discursos sobre infância, neste momento, é, portanto, entender que os princípios geradores do anarquismo propõem uma racionalidade distinta para o uso social da ciência, assim como para a produção de conhecimento e as relações de poder envolvidas nas esferas institucionais nos lugares-comuns ao conhecimento científico-formal; proposições estas que divergem da colonialidade e, como afirma (SANTOS, 2007) ao apontar os desafios de problematizar o pensamento colonial, concebem o próprio conhecimento como um princípio de solidariedade. Pode-se então pensar que os princípios geradores do anarquismo se mostram em grande potencial epistemológico para responder algumas inquietações para a proposição e desenvolvimento de uma teoria concisa acerca do pensamento decolonial nos estudos sobre infância.

Martinez (2015) aborda que o pós-colonialismo contribui para os Estudos da Infância ao perceber a categoria de idade como um fator de opressão. Isto porque, em contextos e perspectivas formalmente coloniais, a hierarquização de grupos humanos há ordenamentos raciais, étnicos, de gênero, mas também entre crianças e adultos. O que é perceptível quando educamos, ensinamos e domesticamos crianças para que estas caibam no nosso mundo, no mundo adulto. Na perspectiva escolarizada, onde o corpo é domesticado pela instituição. Isto é perceptível quando o porvir da criança é mais importante que a sua vida atual.

Para ensinar conteúdos é preciso acontecer um anestesiamento dos corpos, controlar, encaixotar, amarrar, capturar, não os deixar mexer. Ensinar já é tanto de violência e prepotência, é apontamento soberbo, coisa de quem sabe do outro, o que é melhor para ele, o que pode salvar. E como certamente o ensino é a pior forma de aprender, é preciso amarrar o corpo tão movente, para conseguir colocar algum foco da mente na transmissão a ser ensinada. Por falta de desejo de quem recebe, controle e ordenamento são necessários. Abafar o corpo tão desejoso de prazer e sentido é urgente no modelo de ensinagem massiva. Então, para ensinar sem desejo do estudante, é preciso adestrar os vetores, os afetos, as percepções, as 
sensibilidades. Para ensinar, na perspectiva unicamente escolarizada e institucional, se faz necessária a anestesia. Anestesia da autonomia, do reconhecimento do outro enquanto sujeito potente. Em especial, quando falamos sobre a educação de crianças pequenas, é importante considerar que a complexidade das especificidades sobre as culturas infantis por estarem subordinadas a uma visão adultocêntrica que as anula enquanto indivíduos.

Tudo isto para compreender que através do ensino diretivo, hierarquizado (adulto-criança) como crença de educação legitimada, a anestesia, sim se faz necessária. Então para possibilitar outra manifestação da educação que se dê através da vontade do aprendente, por uma pedagogia da estesia, do sensível, precisamos mudar o paradigma de abordagem. A vontade do aprendente é um indício fundante, vontade de aprender. Através da vontade é que a criação tem chances de acontecer, pela ensinagem as coisas já vem prontas, em ordem. O aprendente, que precisa construir, elaborar, percorrer seu caminho de aprendizagem, vem pela potência e necessita inventar. Neste tipo de caminho, a sensibilidade, o sensível, é eixo movente, é fator propulsor de produção, corpos anestesiados não conseguem criar, precisam papinha pronta enfiada na boca.

A desescolarização, uma prática intrinsecamente anarquista de auto-gestão educacional, ao almejar novas possibilidades de criações educativas que honrem tanto o corpo quanto o pensamento em suas práticas. A desescolarização se apresenta como uma proposta que identifica grandes falhas no sistema legitimado de escolarização.

Ao perceber os problemas desta instituição escolar e identificar que este espaço se foca em escolarizar e não em educar, é que a desescolarização começa a atuar como proposta de tensionamento, proposta de desintoxicação das submissões corporais e mentais impostas através da escolarização. O prefixo des, aparentemente nega a escola, mas a vivência e experimentação das práticas mostram muito mais. A desescolarização não se foca em acabar com a escola, não se contrapõe à escola, não é contra a escola.

A desescolarização se propõe a experimentar criações educativas, e percebendo a dureza e resistência nos espaços escolares institucionalizados, um 346 childhood \& philosophy, rio de janeiro, v. 13, n. 27, maio-ago. 2017, pp. 335-352 issn 1984-5987 
fechamento às experimentações, se resolve simplesmente explorar possibilidades de ações educativas fora da escola. Uma pergunta recorrente aos praticantes da desescolarização é de porque estas ações não são feitas dentro das escolas, porque se investe energia em criar atividades paralelas e independentes quando existe um ambiente, um espaço em nossa sociedade para pensar estas questões educacionais? Muitas respostas até indicam a possibilidade de haver atividades desescolarizadas dentro de escolas, e até alguns acreditam na possibilidade de desescolarizar uma escola, porém a realidade de muitas instituições demonstra uma resistência muito grande frente a qualquer tentativa de transformação ou de simplesmente alguma proposta de experimentação do novo. A operação de inúmeras instituições escolares pode ser nomeada como estados de dominação, que são aspectos totalizantes das relações de poder: “[...] nas relações humanas há todo um conjunto de relações de poder que podem ser exercidas entre indivíduos, no seio de uma família, em uma relação pedagógica, no corpo político" (FOUCAULT, 2010, p. 2).

Quando estas relações de poder apresentam aspectos de imutabilidade, bloqueios, ou demasiadas resistências, se configura com o que se pode chamar de estados de dominação. É um estado, pois é um estar que permanece o mesmo, e manifesta sua dominação por privar uma das partes de exercer suas práticas de liberdade como cuidado de si, desta forma as expressões são privadas, as vontades não são ouvidas e qualquer tentativa de mudança é rapidamente desqualificada e rechaçada.

Essa análise das relações de poder constitui um campo extremamente
complexo; ela as vezes encontra o que se pode chamar de fatos, ou
estados de dominação, nos quais as relações de poder, em vez de serem
móveis e permitirem aos diferentes parceiros uma estratégia que os
modifique, se encontram bloqueadas ou cristalizadas. Quando um
indivíduo ou grupo social chega a bloquear um campo de relações de
poder, a torná-las imóveis e fixas e a impedir qualquer reversibilidade do
movimento - por instrumentos que tanto podem ser econômicos quanto
políticos ou militares -, estamos diante do que se pode chamar de um
estado de dominação. É lógico que, em tal estado, as práticas de
liberdade não existem, existem apenas unilateralmente ou são
extremamente restritas e limitadas. (FOUCAULT, 2010, p. 2)

Esta dominação e controle demasiado gera uma escassa troca de escuta das partes tornadas submissas, as crianças ou os estudantes, no caso da escola. Muitas 
atitudes violentas decorrem do abafamento sistemático da liberdade, a parte da relação de poder que se encontra em posição de submissão acaba reagindo frente a ausência de vislumbre de criação, se vendo apenas tendo que repetir o que de seu corpo e pensamento é solicitado - a colonização do pensamento e do corpo, especialmente infantil.

Para descolonizar o pensamento e as práticas é fundamental a constituição de pedagogias da infância que favoreçam compreender - e combater - as desigualdades de um pensamento colonizado, individualista, com os desejos e os corpos em um estado de limitação constante e opressão das especificidades dos indivíduos - que não responde as urgências e mantém o estado de desigualdade: o status quo das práticas em Educação Infantil.

Pedagogias que apontem alternativas desde a Educação Infantil, que se constituam com variedade de formas, com artefatos críticos, com docentes preparados a interpor. Um exemplo interessante de material que pode problematizar os modos de educar as crianças e que podem ser usados pelos professores, pais e crianças é o livro A Rule Is To Break: A child's guide to anarchy 4 (Uma regra é para ser quebrada: um guia infantil para anarquia), um dos poucos materiais infantis que se dedicam a explorar a concepção de educação anarquista.. Nele, os autores exploram a resistência infantil de maneira educativa e lúdica, assim como afirmam os textos anarquistas e pós-coloniais. Neste material, podemos perceber uma aproximação do movimento de resistência anarquista com concepção pós-colonial sobre a infância.

\footnotetext{
${ }^{4}$ Não há tradução oficial para o português e não há venda deste material no Brasil

348 childhood \& philosophy, rio de janeiro, v. 13, n. 27, maio-ago. 2017, pp. 335-352 issn 1984-5987
} 


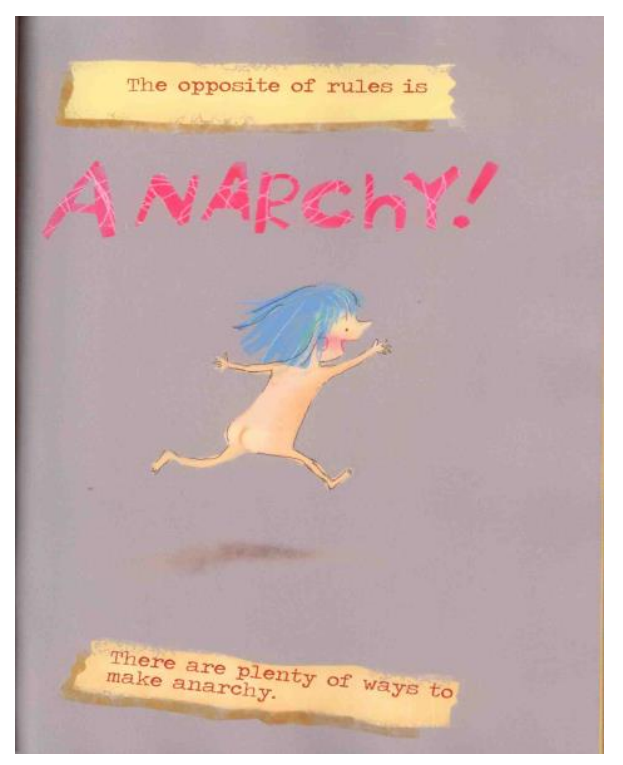

Figura 2: "The opposite of rules is anarchy: there are plenty of ways to make anarchy." Imagem retirada do livro A Rule Is To Break. ${ }^{5}$

Este pode ser considerado um material pedagógico que questiona e diverge da racionalidade científica e do regime educacional colonizado, pois diz que as regras prontas, afirmadas pelos adultos, podem ser questionadas e que distribuir entre todos é melhor que ter a propriedade privada, ideias convergentes entre o paradigma pós-colonialista e anarquista.

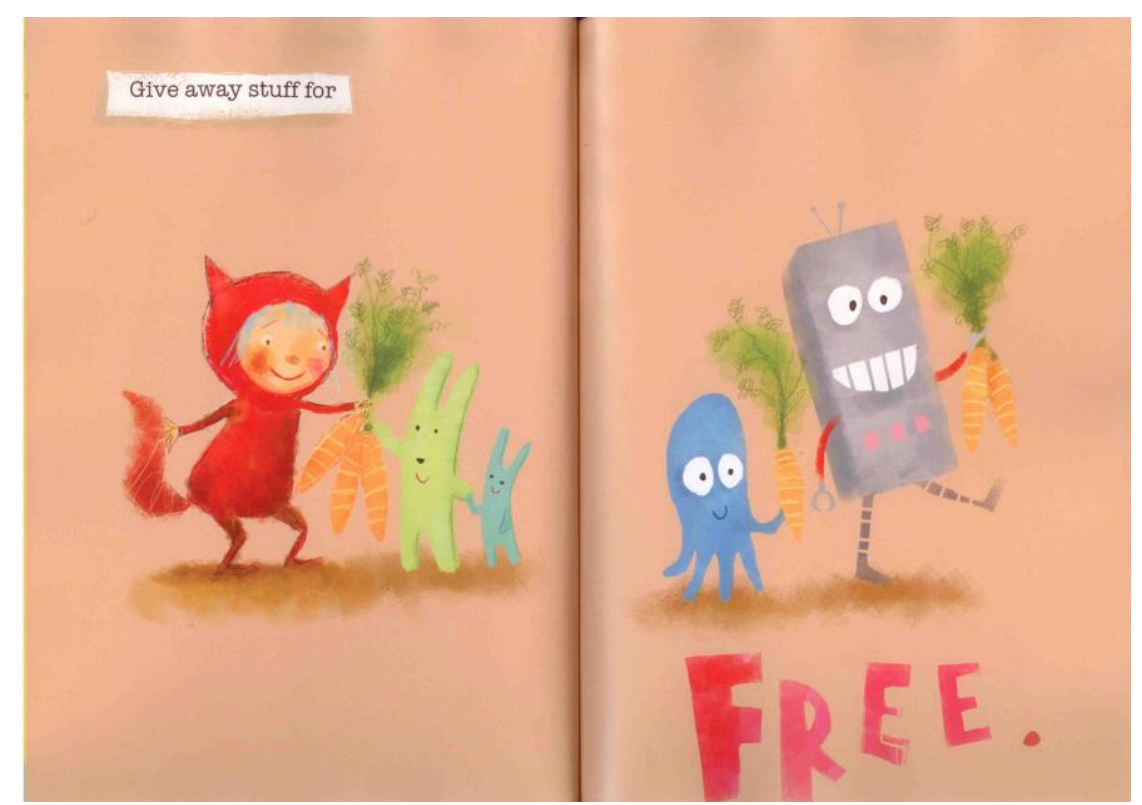

Figura 3: "Give away stuff of free." Imagem retirada do livro A Rule Is To Break. ${ }^{6}$

\footnotetext{
${ }^{5}$ Tradução: "O oposto das regras é ANARQUIA! Existem muitas maneiras de fazer anarquia." (tradução feita pelas autoras).

${ }^{6}$ Tradução: "Dê as coisas de GRAÇA!" (tradução feita pelas autoras). 


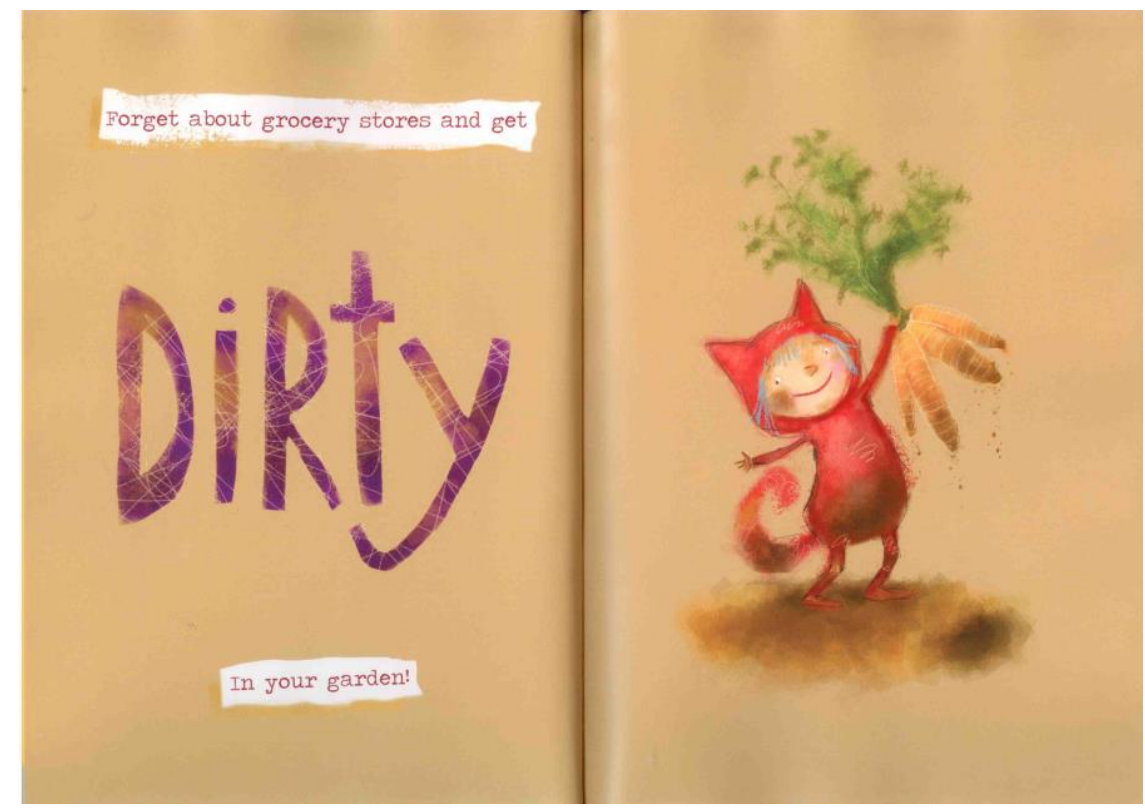

Figura 4: "Forget about grocery stores and get dirty in your Garden!" Imagem retirada do livro A Rule Is To Break. ${ }^{7}$

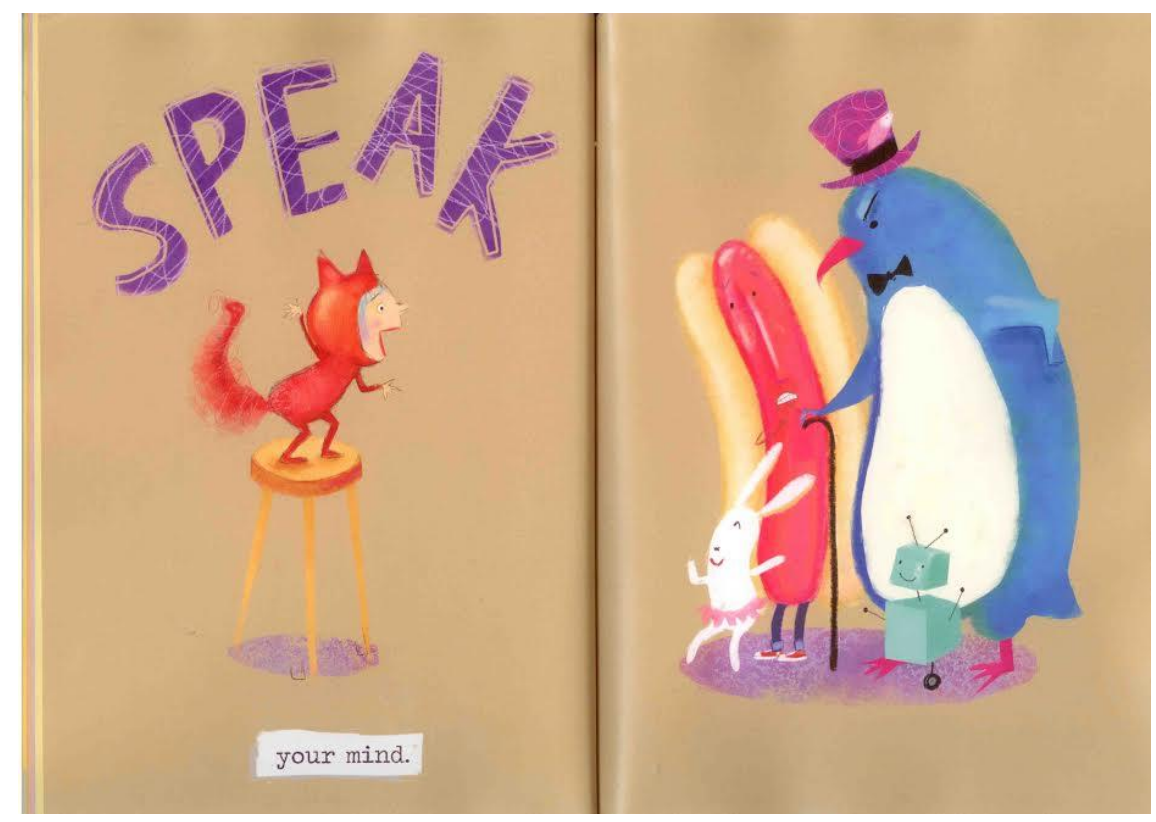

Figura 5: “Speak your mind." Imagem retirada do livro A Rule Is To Break. ${ }^{8}$

\footnotetext{
7 Tradução: "Esqueça os supermercados e se suje no seu quintal" (tradução feita pelas autoras). 8 Tradução: "Dê sua opinião." (tradução feita pelas autoras).
} 


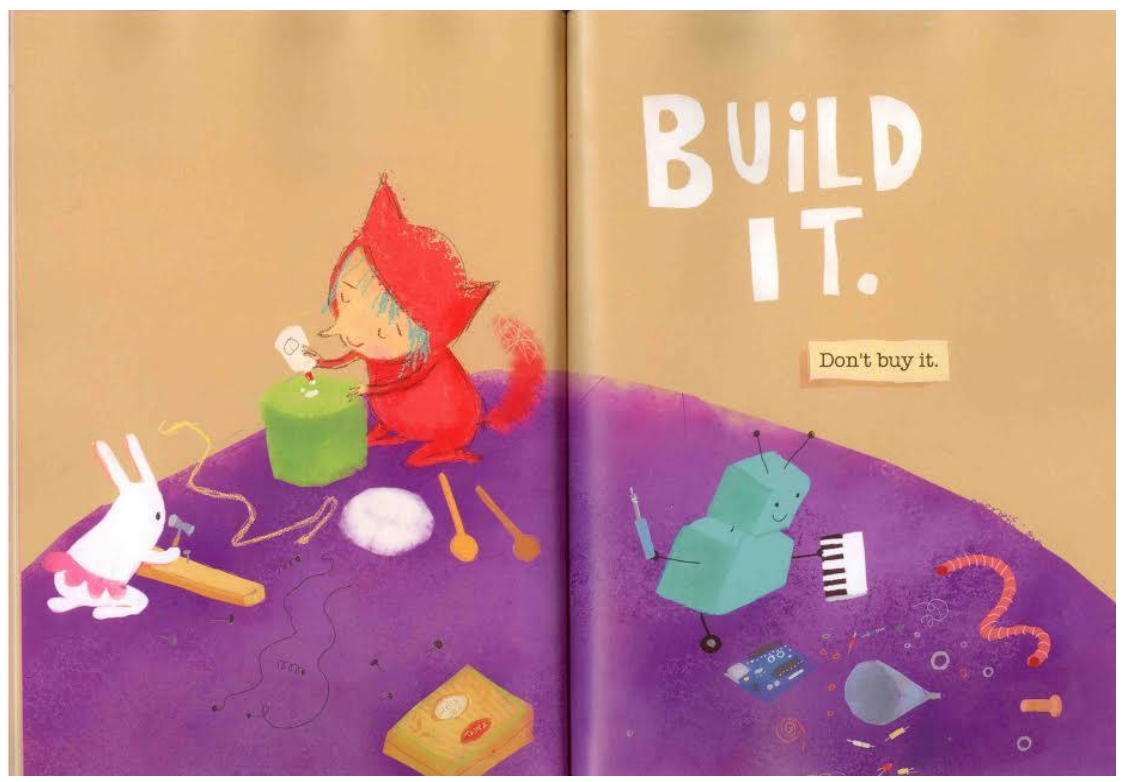

Figura 6: “Build it. Don't buy it." Imagem retirada do livro A Rule Is To Break. ${ }^{9}$

Podemos articular as concepções Pós-Colonialistas (ou decolonialistas) à Educação Anarquista? Não sabemos ainda, porém, podemos afirmar que se a construção politica e acadêmica dos campos de saber se deram de modos distintos e em tempos e espaços sociais diferenciados, ambas as teorias se aproximam ao defenderam as resistências aos poderes globais, aos saberes descontextualizados e aos seres homogeneizados.

\section{referências}

BALLESTRIN, Luciana. América Latina e o giro decolonial. Revista Brasileira de Ciência Política, Brasília, nº 11, pp. 89-117, maio/ago, 2013.

DUSSEL, Enrique. Europa, Modernidade e Eurocentrismo. In: LANDER, Edgardo (org.). A Colonialidade do saber: eurocentrismo e ciências sociais. Perspectivas latino-americanas. ColecciónSurSur, CLACSO, Ciudad Autónoma de Buenos Aires, Argentina. Setembro 2005. Disponível em: <http:// biblioteca.clacso.edu.ar/ar/libros/lander/pt/lander.html> Acesso em: maio de 2016.

FARIA, Ana Lúcia Goulart (org). et al. Infâncias e Pós-Colonialismo: pesquisas em busca de Pedagogias descolonizadoras. Campinas: Leitura Crítica, 2015.

FOUCAULT, Michel. A ética de si como prática de liberdade. In: Ética, sexualidade, política. Rio de Janeiro: Forense Universitária, 2010. (Coleção Ditos e escritos). v.5. p. 264293.

GALLO, Sílvio. Pedagogia Libertária: Anarquistas, Anarquismos e Educação. Editora Imaginário e EDUA - Editora da Universidade Federal do Amazonas: Manaus, 2007.

\footnotetext{
9 Tradução: “Construa você mesmo, não compre” (tradução feita pelas autoras). 
anarquismo e descolonização: possibilidades para pensar a infância

MARTINEZ, Laura Victoria. Infancia y poscolonialidad. Recorridos y debates teóricos desde América Latina. II Congreso de Estudios Poscoloniales | III Jornadas de Feminismo Poscolonial. Diciembre, 2014. Disponível em: <http://www.idaes.edu.ar/pdf_papeles/M1\%20-\%209\%20-\%20Martinez.pdf> Acesso em dezembro de 2015.

RODRIGUES, Edgar. Pequeno Dicionário de Ideias Libertárias. 3 ed. CC\&P Editores, 1999.

SEVEN, John. CHRISTY Jana. A rule is to break: a child's guide to anarchy. Manic D Press: San Francisco (USA), 2012.

SANTOS, Boaventura de Sousa. Reinventar a teoria crítica e reinventar a emancipação social. São Paulo: Boitempo, 2007.

VIRURU, Radhika. The impact of postcolonial theory on early childhood education. Journal of Education, n. 35, 2005.

recebido em: 23.12.2016

aprovado em: 02.02.2017 